\title{
UPAYA GURU DALAM MENINGKATKAN KECERDASAN SPIRITUAL ANAK USIA DINI DI RA MUSLIMAT NU NURUD DHOLAM
}

\author{
Faizzatul Hasanah \\ IAIN Madura \\ Email: faizzatulhasanah11@gmail.com
}

\begin{abstract}
Spiritual intelligence is intelligence that is owned by individuals in relation to values and behavior. A person equpped with spiritual intelligence is expected to take behavior and pay attention to its value. Considering that spiritual intelligence is important for early childhood, the teacher at RA Muslimat NU Nurud Dholam also stimulates children's spiritual intelligence in various efforts. The methode used in this study is a qualitative descriptive study with data source of class teachers and students guardians of RA Muslimat NU Nurud Dholam, and RPPH documents. The data collection technique the author did was observation than continued with semi-structured interviews wich were recorded in the form of documention in the form of learning activities carried out by RA Muslimat NU Nurud Dholam. Efforts made by teachers in RA Muslimat NU Nurud Dholam in the form of plaining habitation in accordance with the values of islamic religious teaching (based on al-Qur'an and hadits), such as reading the hadits and its aplication, daily prayers, short surah, manners, ibadah practices(ablution, adzan and iqomah, and prayer) with gradual delivery, adapted to the abilities and stages of child development.
\end{abstract}

Keywords: Teachers Efforts; Spiritual Intelligence; Early Childhood

\begin{abstract}
Abstrak
Kecerdasan spiritual adalah kecerdasan yang dimiliki oleh individu dalam kaitannya dengan nilai dan perilaku. Seseorang dibekali dengan dengan kecerdasan spiritual diharapkan dalam mengambil perilaku juga memperhatikan nilainya. Mengingat kecerdasan spiritual ini penting untuk anak usia dini, maka guru di RA Muslimat NU Nurud Dholam juga ikut menstimulus kecerdasan spiritual anak dalam berbagai upaya. Metode yang digunakan dalam penelitian ini adalah penelitian deskriptif kualitatif dengan sumber data guru kelas dan wali murid RA Muslimat NU Nurud Dholam, dan dokumen RPPH. Teknik pengumpulan data yang penulis lakukan adalah observasi kemudian dilanjutkan dengan wawancara semi-terstruktur yang dicatat dalam bentuk dokumentasi berupa kegiatan pembelajaran yang dilakukan RA Muslimat NU Nurud Dholam. Upaya yang dilakukan guru di RA Muslimat NU Nurud Dholam berupa penanaman pembiasaan-pembiasaan sesuai nilai-nilai ajaran agam Islam (didasarkan pada al-Qur'an dan hadits), seperti bacaan hadits dan penerapannya, doa-doa harian, surah-surah pendek, adab, praktek ibada (wudhu', adzan dan iqomah, serta sholat) dengan penyampaian secara bertahap, disesuaikan dengan kemampuan dan tahap perkembangan anak.
\end{abstract}

Kata Kunci: Upaya Guru; Kecerdasan Spiritual; Anak Usia Dini 


\section{PENDAHULUAN}

Anak usia dini (AUD) adalah individu yang sedang mengalami proses pertumbuhan dan perkembangan yang sangat pesat, bahkan dikatakan sebagai lompatan perkembangan. Anak usia dini memiliki rentang usia yang sangat berharga dibanding usia-usia selanjutnya karena perkembangan kecerdasannya sangat luar biasa (Mulyasa, 2014:16). Pada masa ini anak mengalami peningkatan dari $50 \%$ menjadi $80 \%$, sehingga pada usia ini disebut usia emas (golden age) (Halimah, 2019: 1).

Dengan kecerdasan yang dimiliki ini, menurut Astuti \& Aziz (2019: 296) mereka perlu mendapatkan pembinaan yang tepat yang memungkinkan anak untuk mengembangkan potensi dan kemampuannya itu secara optimal. Pembinaan tersebut dicanangkan pemerintah berupa pendidikan anak usia dini.

Dalam Peraturan Menteri Pendidikan dan Kebudayaan (Permendikbud) Nomor 146 Tahun 2014 tentang Kurikulum 2013 Pendidikan Anak Usia Dini pasal 1 bahwa pendidikan anak usia dini merupakan suatu upaya pembinaan yang ditujukan kepada anak sejak lahir sampai dengan usia 6 (enam) tahun yang dilakukan melalui pemberian rangsangan pendidikan untuk membenatu pertumbuhan, perkembangan jasmani dan rohani supaya anak siap dalam memasuki pendidikan lebih lanjut.

Terdapat 6 aspek perkembangan yang harus dikembangkan dalam program PAUD, yaitu nilai agama dan moral, fisik motorik, kognitif, bahasa, sosial emosional, dan seni, sesuai dengan keunikan dan tahap-tahap perkembangan sesuai kelompok usia yang dilalui oleh anak usia dini seperti yang tercantum dalam Permendikbud Nomor 137 Tahun 2014 tentang Standar Nasional PAUD. Untuk memberikan stimulus yang tepat untuk semua aspek tersebut diperlukan guru.

Guru adalah seorang pendidik yang bertugas, membimbing, serta mengajarkan suatu ilmu secara profesional yaitu dengan melatih, mengarahkan agar anak dapat memahami ilmu pengetahuan yang diajarkan, melakukan penilaian dan evaluasi kepada peserta didik (Halimah, 2019: 1). Menurut Sujiono (2013: 10) guru diidentifikasikan sebagai: (1) orang yang memiliki kharisma atau wibawa hingga perlu untukditiru dan diteladani, (2) orang dewasa yang secara sadar bertanggung jawab dalam mendidik, mengajar dan membimbing anak, (3) orang yang memiliki kemampuan merancang program pembelajaran serta mampu menata dan mengelola kelas dan (4) suatu jabatan atau profesi yang memerlukan keahlian khusus.

Guru juga merupakan orang yang bertanggung jawab terhadap perkembangan anak didik yaitu baik perkembangan jasmani ataupun rohani (Atmaka, 2004:17). Peran guru terhadap pendidikan anak usia dini sangatlah penting dalam mengembangkan keenam aspek perkembangan anak usia dini (Apriyanti, 2017: 112).

Seperti yang telah dibahas dalam pengertian guru dan tujuan PAUD bahwasannya pendidikan tidak hanya difokuskan pada pertumbuhan dan perkembangan jasmani atau intelektual anak, namun juga fokus dalam pertumbuhan dan perkembangan rohani anak usia dini (dalam aspek nilai agama dan moral) melalui stimulus untuk meningkatkan kecerdasan spiritual (Spiritual Question).

Menurut Danah Zohar dan Ian Marshall (dalam Annisa, 2017: 3), kecerdasan spiritual adalah kecerdasan untuk menghadapi persoalan makna dan nilai atau value, yaitu kecerdasan untuk menempatkan perilaku dan hidup kita dalam konteks makna yang lebih luas dan kaya, kecerdasan untuk menilai bahwa atau jalan hidup seseorang lebih bermakna dibandingkan dengan yang lain. SQ adalah landasan yang diperlukan untuk memfungsikan IQ dan EQ secara efektif. Bahkan merupakan kecerdasan tertinggi. Dalam pandangan Islam, kecerdasan spiritual adalah kemampuan untuk memberi makna ibadah terhadap setiap perilaku dan kegiatan, melalui langkah-langkah dan pemikiran tauhidi (integralistik) serta berprinsip "hanya karena Allah" (Firdaus, 2015: 102). 
Dengan melihat definisi sebelumnya dapat diartikan bahwa kecerdasan spiritual adalah kecerdasan yang dimiliki oleh individu dalam kaitannya dengan nilai dan perilaku. Seseorang dibekali dengan dengan kecerdasan spiritual diharapkan dalam mengambil perilaku juga memperhatikan nilainya. Apakah perilaku tersebut sesuai dengan nilai yang berlaku atau bahkan melanggar. Maksud dari nilai niai secara lebih luas dapat dimaknai dari sumber yang beragam seperti nilai yang bersumber dari agama, maupun dasar negara. Namun secara umum kedua sumber nilai tersebut tetap berjalan beriringan dan saling menguatkan (Nuryanto, 2017: 43). Kecerdasan spiritual adalah kecerdasan yang dimiliki oleh setiap manusia, maka akan lebih optimal pengembangannya ketika mulai diasah sejak dini atau mulai sejak usia anak-anak (Hidayatul, 2018: 3).

Berkaitan dengan kecerdasan spiritual anak, permasalahan yang sering terjadi dikalangan masyarakat masa kini adalah orang tua lebih banyak memaksa anak untuk mengeksplorasi bentuk kecerdasan yang lain, khususnya kecerdasan intelektual. Sehingga anak sejak awal sudah ditekankan untuk selalu bersaing dan menjadi yang terbaik dan mengesampingkan perkembangan kecerdasan dan kebutuhan spiritual dalam diri anak. Guru sebagai pendidik yang memahami bahwa kecerdasan spiritual itu penting untuk perkembangan anak kelak, harus mampu menjadi jembatan penghubung antara guru dengan keluarga maupun dengan masyarakat. Hal ini dikarenakan semua komponen itu penting dan mejadi faktor perkembangan kecerdasan spiritual anak.

Mengingat kecerdasan spiritual ini penting untuk anak usia dini, maka guru di RA Muslimat NU Nurud Dholam juga ikut menstimulus kecerdasan spiritual anak dalam berbagai upaya. Hal ini sekaligus memberikan pemahaman kepada orang tua bahwa jiwa anak juga perlu diberi rangsangan agar perilaku/sikap anak mampu mencerminkan nilai-nilai positif atau perilaku ketauhidan. Penelitian ini dilakukan di RA Muslimat NU Nurud Dholam karena lembaga tersebut berada dibawah naungan Kemenag (Kementerian Agama), sehingga peneliti tertarik untuk mengetahui upaya guru dalam meningkatkan kecerdasan anak usia dini di RA Muslimat NU Nurud Dholam.

\section{METODE PENELITIAN}

Metode yang digunakan dalam penelitian ini adalah penelitian deskriptif kualitatif, yaitu penelitian yang dilakukan melalui pendekatan kualitatif dan dideskripsikan dalam bentuk kata-kata tertulis atau lisan dari orang dan perilaku yang dapat diamati (Moleong, 2011: 4). Sehingga peneliti mengakaji data dari RA Muslimat NU Nurud Dholam yang kemudian mendeskripsikan data tersebut sesuai dengan realita. Subjek dalam penelitian adalah pihakpihak yang terkait dan memiliki peran penting di RA Muslimat NU Nurud Dholam. Adapun sumber data dalam penelitian dibagi menjadi dua kategori, yaitu kategori manusia dan non manusia. Sumber data kategori manusia yaitu guru kelas dan wali murid RA Muslimat NU Nurud Dholam. Sedangkan sumber data non manusia adalah dokumen RPPH. Ada 2 teknik pengumpulan data yang dilakukan peneliti, yaitu observasi, kemudian dilanjutkan dengan wawancara semi-terstruktur yang dicatat dalam bentuk dokumentasi berupa kegiatan pembelajaran yang dilakukan RA Muslimat NU Nurud Dholam untuk meningkatkan kecerdasan spiritual anak. penelitian ini dilakukan di RA Muslimat NU Nurud Dholam Desa Majungan Kecamatan Pademawu Kabupaten Pamekasan yang dilaksanakan selama dua hari, yaitu hari senin dan sabtu. Mengenai pengecekan keabsahan hasil penelitian, peneliti menggunakan teknik keikutsertaan, ketekunan pengamatan dengan mengamati perkembangan anak di sekolah, serta triangulasi dimana peneliti membandingakan data dengan teori terdahulu. 


\section{HASIL DAN PEMBAHASAN}

Pada dasarnya setiap anak di RA Muslimat NU Nurud Dholam memiliki potensi yang sama dengan kemampuan yang berbeda dan berhak untuk dikembangkan. Dalam hal ini khususnya kecerdasan spiritual, karena anak terlahir fitrah (suci) maka sudah kewajiban seorang pendidik dari lembaga tersebut untuk berupaya bagaimana anak didiknya mampu cerdas tidak hanya dari segi intelektual saja, namun dari segi spiritual (nilai dan perilaku). Terlebih lagi RA Muslimat NU Nurud Dholam berada dalam naungan Kementerian Agama (Kemenag) yang tentunya lebih menekankan terhadap penanaman niai-nilai agama sejak dini.

Berdasarkan penuturan guru, Kemenag memberikan himbawan kepada lembaga dalam proses pembelajaran harus mengacu pada dua hal yaitu al-Qur'an dan hadits. Maksudnya hal pertama yang harus diberikan kepada anak berupa pengenalan pengetahuan tentang al-Qur'an dan hadits. Bentuk pengenalan ini biasanya dilakukan dengan cara bermain, bernyanyi, bercerita ataupun melalui praktek langsung. Yang terpenting adalah penyampaiannya harus bertahap, disesuaikan dengan kemampuan dan tahap perkembangan anak (Hoiriyah: Wawancara).

Hal tersebut sesuai dengan pendapat Sujiono (2013: 2) bahwasannya proses pembelajaran pada anak usia dini hendaknya dilakukan dengan tujuan memberikan konsepkonsep dasar yang memiliki kebermaknaan bagi anak melalui pengalaman nyata yang memungkinkan anak untuk menunjukan aktivitas dan rasa ingin tahu (coriousity) secara optimal. Dalam hal ini pengenalan pembelajaran al-Qur'an dan hadits pada anak usia dini harus tetap memperhatikan karakteristik anak dalam belajar dan mampu memberikan pemahaman serta penerapan dalam kehidupan sehari-hari sehingga sikap dan perilaku anak mencerminkan nilai-nilai ajaran Islam.

Pembiasaan yang diterapkan di RA Muslimat NU Nurud Dholam di dasarkan atas sunah nabi, seperti kebiasaan anak tidak boleh meniup makanan, minum tidak boleh berdiri, mengucapkan salam beserta dengan bunyi dan makna haditsnya. Dalam kegiatan ibadah, lembaga memiliki kegiatan khusus yang dilaksanakn setiap hari sabtu berupa praktek ibadah wudhu, adzan dan iqomah serta sholat (bacaan dan gerakan) yang didemonstrasikan langsung oleh guru dan anak (Hoiriyah: Wawancara).

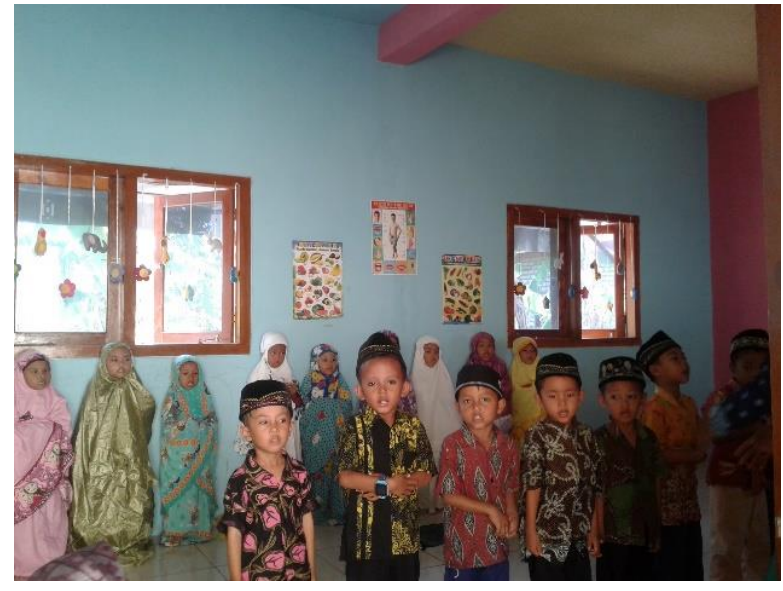

\section{Gambar 1. Pelaksanaan kegiatan praktek sholat}

Dalam meningkatkan kecerdasan spiritual anak di RA Muslimat NU Nurud Dholam, guru memasukkan pembiasaan-pembiasaan ke dalam rencana pelaksanaan pembelajaran harian (RPPH) berupa pembiasaan doa harian sebelum masuk kelas, doa sebelum melakukan kegiatan dan mencium tangan guru secara bergiliran, doa-doa dan hadits pilihan lainnya serta surah-surah pendek (Hoiriyah: Wawancara). Semua pembiasaan itu 
diintegrasikan oleh guru dalam setiap pembelajaran agar anak mampu menerapkan baik dalam lingkungan sekolah, lingkungan keluarga, maupun dalam lingkungan masyarakat.

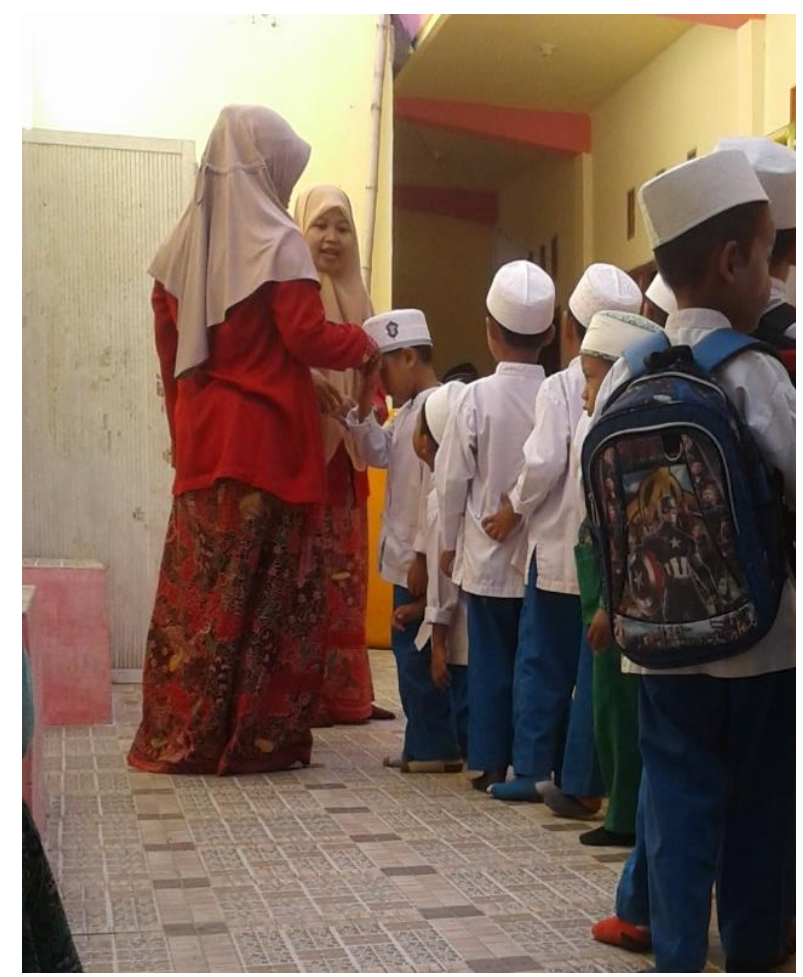

\section{Gambar 2. Penerapan Pembiasaan mencium tangan guru sebelum masuk kelas}

Pembiasaan mencium tangan tersebut adalah bentuk mengajarkan anak cara menghormati guru (orang yang lebih tua), sehingga anak bisa menerapkan pembiasaan mencium tangan orang tua dan orang yang lebih tua sebelum dan sesudah pulang sekolah (Hoiriyah: Wawancara). Manfaat dari pembelajaran pembiasaan itu sangat dirasakan oleh wali murid. Menurut salah satu wali murid (Dian: Wawancara) anak yang sebelumnya berangkat tanpa mencium tangan, setelah berlangsung beberapa hari anak mulai mencium tangan orang tua dan anggota keluarga lainnya dengan menggunakan kedua tangannya sesuai dengan yang diajarkan oleh guru di sekolah. Tidak hanya itu, ternyata anak juga menerapkan membaca doa sebelum makan, mengucapkan salam ketika mau berangkat sekolah, dan mengikuti gerakan sholat ketika orang tua melakukan sholat. Bahkan anak juga sering mengingatkan dengan berkata "ayo sholat, kalau gak sholat nanti Allah marah".

Pembiasaan-pembiasaan melalui penanaman nilai-nilai keagamaan yang diterapkan di RA Muslimat NU Nurud Dholam sesuai dengan pendapat Firdaus (2015: 107) bahwa nilai-nilai keagamaan yang sangat penting untuk ditanamkan kepada anak dalam mengembangkan dimensi spiritualnya diataranya: (1) penanaman takwa melalui ibadah shalat, puasa, mengaji dan lainnya, (2) pengajaran dzikir dan berdoa setiap akan melakukan sesuatu apapun, (3) pembentukan kesabaran, (4) penanaman amal sholeh, dan (5) pembentukan ajaran istiqomah. Selaras dengan pendapat di atas, Hamdan Rajih (dalam Firdaus, 2015: 107) menambahkan bahwa salah satu kiat-kiat dalam membimbing dan mendidik anak menjadi lebih cerdas secara spiritual dan beradab adalah memanfaatkan metode dakwah Rasulullah saw. yaitu metode pendekatan keteladanan, memaksimalkan pemanfaatan waktu dan peluang bersama anak untuk memberikan pengarahan, sikap adil terhadap anak-anak, mengaktifkan potensi berpikir anak, dan mengembangkan mental anak. 
Untuk mengetahui berhasil atau tidaknya penerapan pembiasaan, guru mengevaluasi anak dengan cara observasi. Untuk implementasi hadits, guru menilai apakah terlihat perubahan dari sikap dan perbuatan anak untuk tidak membuang sampah sembarangan setelah anak diajarkan hadits "annadhofatu minal iman". Sedangkan pembiasaan ibadah, bentuk observasinya dari segi gerakan dan bacaan sholat anak, apakah anak sudah bisa mengikuti secara mandiri atau masih dalam arahan guru. Pada dasarnya semua pembiasaan baik doa-doa, adab, hadits serta ibadah diajarkan secara bertahap oleh guru. Jika dirasa anak belum mampu untuk mencapai satu pembelajaran baik dari bacaan dan sikapnya, maka guru tidak akan melanjutkan ke pembelajaran berikutnya (Hoiriyah: Wawancara). Oleh karena itu, penting bagi guru untuk dapat mengerti cara berfikir anak, mengembangkan dan menghargai pengalaman anak, memahami bagaiman anak mengatasi suatu persoalan, menyediakan dan memberikan materi sesuai dengan taraf perkembangan kognitif anak agar lebih berhasil membantu anak berfikir dan membentuk pengetahuan (Sujiono, 2013: 13).

\section{KESIMPULAN}

Setiap anak memliki potensi yang sama dan terlahir secara fitrah (suci) sehingga sudah tugas seorang guru dalam sebuah sekolah untuk mendidik dan mengarahkan anak agar lebih cerdas secara spiritual. Upaya yang dilakukan guru di RA Muslimat NU Nurud Dholam berupa penanaman pembiasaan-pembiasaan sesuai nilai-nilai ajaran agam Islam (didasarkan pada al-Qur'an dan hadits). Pembiasaan-pembiasaan itu berupa bacaan hadits dan penerapannya, doa-doa harian, surah-surah pendek, adab kepada orang lain (orang tua, guru maupun orang lebih tua/muda), praktek ibadah (wudhu', adzan dan iqomah, serta sholat) yang disampaikan melalui metode bermain, bernyanyi, bercerita ataupun melalui praktek langsung. Yang terpenting adalah penyampaiannya harus bertahap, disesuaikan dengan kemampuan dan tahap perkembangan anak.

\section{DAFTAR PUSTAKA}

Annisa, R. S. (2017). Strategi Guru dalam Pengembangan Kecerdasan Spiritual pada Anak Usia Dini di RA Al-Wathoniyah Jabon Kalidawir Tulungagung. Skripsi. Tidak diterbitkan. Fakultas Tarbiyah dan Ilmu Keguruan. Institut Agama Islam Tulungagung Tulungangung

Apriyanti, H. (2017). Pemahaman Guru Pendidikan Anak Usia Dini terhadap Perencanaan Pembelajaran Tematik. Jurnal Obsesi: Jurnal Pendidikan Anak Usia Dini, 1(2), 111117.

Astuti, R. \& Aziz, T. (2019). Integrasi Pengembangan Kreativitas Anak usia Dini di TK Kanisius Sorowajan Yogyakarta. Jurnal Obseso: Jurnak Pendidikan Anak Usia Dini, 3(2), 294-302.

Atmaka, Dri. (2004). Pengantar Pendidikan. Salatiga: Widyasari Press.

Firdaus. (2015). Membangun Kecerdasan Spiritual Islami Anak Usia Dini. Al-Adyan, 10(1), 99-112.

Halimah, S. Upaya Guru dalam Pembentukan Akhlak Anak di Raudlotul Athfal Baipas Raidlotul Jannah Kota Malang. Jurnal Dewantara, 1(1), 1-6.

Mulyasa, E. (2014). Manajemen PAUD. Bandung: Remaja Rosdakarya. 
Hidayatul, A. (2018). Mengembangkan Kecerdasan Spiritual AnakUsian Dini Melalui Metode Cerita Islmi di TK ABA Carikan Muntilan. Skripsi. Fakultas Ilmu Tarbiyah dan Ilmu Keguruan. UIN Sunan Kalijaga: Yogyakarta.

Nuryanto, S. (2017). Stimulus Kecerdasan Spiritual pada Anak Usia Dini Melalui Kisah. Jurnal Indria: Jurnal Ilmiah Pendidikan Prasekolah dan Sekolah Awal, 11(2), 4155.

Peraturan Menteri Pendidikan dan Kebudayaan Nomor 146 Tahun 2014 Tentang Kurikulum 2013 Pendidikan Anak Usia Dini.

Peraturan Menteri Pendidikan dan Kebudayaan Nomor 137 Tahun 2014 Tentang Standar Nasionalpendidikan Anak Usia Dini.

Sujiono, Yuliani Nurani. (2013). Konsep Dasar Pendidikan Anak Usia Dini. Jakarta: Indeks. 